



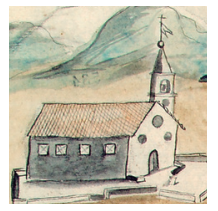




\section{LA ERECCIÓN DE LA ARQUIDIÓCESIS Y SUS PRIMEROS ESFUERZOS EVANGELIZADORES, 1553-1600}

Juan Fernando Cobo Betancourt

Este capítulo examina la llegada del clero secular a Santafé a mediados del siglo XVI y sus primeros esfuerzos por evangelizar a la población indígena hasta el final del siglo. Estos procesos representaron un conflicto con el statu quo en el cual la evangelización y vida religiosa de la región había estado dominada por las órdenes religiosas. Durante los siguientes cincuenta años, la historia de la Arquidiócesis estuvo marcada por un esfuerzo por parte de las autoridades diocesanas por asumir el control del liderazgo de la Iglesia, en competencia con los regulares y las autoridades civiles. Asimismo, en este periodo el proyecto evangelizador estuvo guiado por unas prioridades ideológicas y unas suposiciones acerca de la población indígena y su vida religiosa que respondían a las preocupaciones de la influencia humanística y de la llamada Prerreforma española. El resultado fue una evangelización centrada en la importancia de la catequesis y la extirpación de creencias y prácticas aparentemente precolombinas, pero aun sin la introducción completa de muchos aspectos de la vida religiosa católica cotidiana.

El 3 de junio de 1556 concluyó una reunión extraordinaria en la ciudad de Santafé en el Nuevo Reino de Granada. Parecía que toda la élite local estaba congregada. Funcionarios de los más altos niveles del gobierno civil y la sociedad seglar estaban presentes, entre ellos Francisco Briceño, el presidente de la Real Audiencia, con sus oidores. Incluso se encontraba allí el fundador de la ciudad, Gonzalo Jiménez de Quesada, "en nombre de todas las ciudades de este Reino". También las cabezas de las órdenes religiosas activas en el Nuevo Reino, los franciscanos y dominicos, "y otros muchos religiosos y letrados en leyes y en cánones" (Constituciones, 1556, pp. 562-563). Todos habían venido a ver el cierre del primer sínodo que 
había tenido lugar en la ciudad de Santafé, a ser testigos de cómo el recién llegado clero secular promulgaba su primer corpus de legislación. Presidiendo sobre todos ellos estaba Juan de Los Barrios, entonces arzobispo de Santa Marta y del Nuevo Reino de Granada (obispo 1552-1569).

La historia del clero secular en Santafé era corta. Había empezado con el predecesor de Barrios, fray Martín de Calatayud, obispo de Santa Marta, quien había solicitado al rey que se trasladara su sede a la ciudad de Santafé. La petición fue concedida en febrero de 1549, pero el obispo murió antes de recibir la noticia ${ }^{1}$. De esta manera, la tarea de llevar la Iglesia secular al Nuevo Reino de Granada recayó en Barrios, su sucesor, que había llegado a la ciudad de Santafé en 1553. Este sínodo fue en varios sentidos, el momento fundacional y por lo tanto, este es nuestro punto de partida. Fue la primera legislación sistemática que se expidió para gobernar la entonces diócesis y cubría un amplio rango de temas relacionados a su administración y al gobierno de sus instituciones, incluidas un número de disposiciones importantes sobre la evangelización de la población indígena de la región. A pesar del pomposo ceremonial de la conclusión del sínodo diocesano, la distancia entre la legislación y la realidad no podía ser más marcada.

Todo el clero de la nueva diócesis cabía en un solo salón: unos veinte dominicos, algunos franciscanos y menos de veinte sacerdotes seculares (Lee 1963, p. 10, p. 30). Aun así, existían divisiones profundas entre ellos y la capacidad de Barrios de implementar las directivas de su sínodo era muy limitada. A pesar del respaldo y la cooperación que parecía sugerir la presencia de las autoridades civiles en la clausura, los límites entre la jurisdicción civil y eclesiástica no eran para nada claros. En los próximos cincuenta años, la historia de la Arquidiócesis estuvo marcada por el empeño de las autoridades diocesanas para tomar el liderazgo de la Iglesia y controlar la evangelización de la población indígena, en competencia con los regulares y los funcionarios civiles. Las constituciones del sínodo de 1556, al igual que gran parte de la legislación eclesiástica sancionada en las décadas siguientes, buscaron homogeneizar y sistematizar el programa evangelizador, sometiéndolo a la potestad diocesana. Ninguno de estos esfuerzos fue sencillo.

${ }^{1}$ La más detallada historia de la Arquidiócesis en el siglo XVI continúa siendo el primer volumen de Juan Manuel Pacheco en la Historia Extensa de Colombia (1971), incluso si su perspectiva y suposiciones ahora parecen algo anticuadas. Otro bosquejo útil es el de Luis Carlos Mantilla (1994). 
Figura 1. Anónimo. (s. f.). Arzobispo fray Juan de Los Barrios. En: José Restrepo Posada (1961-1971). Arquidiócesis de Bogotá. Bogotá: Ed. Lumen Kelly, vol. 1.

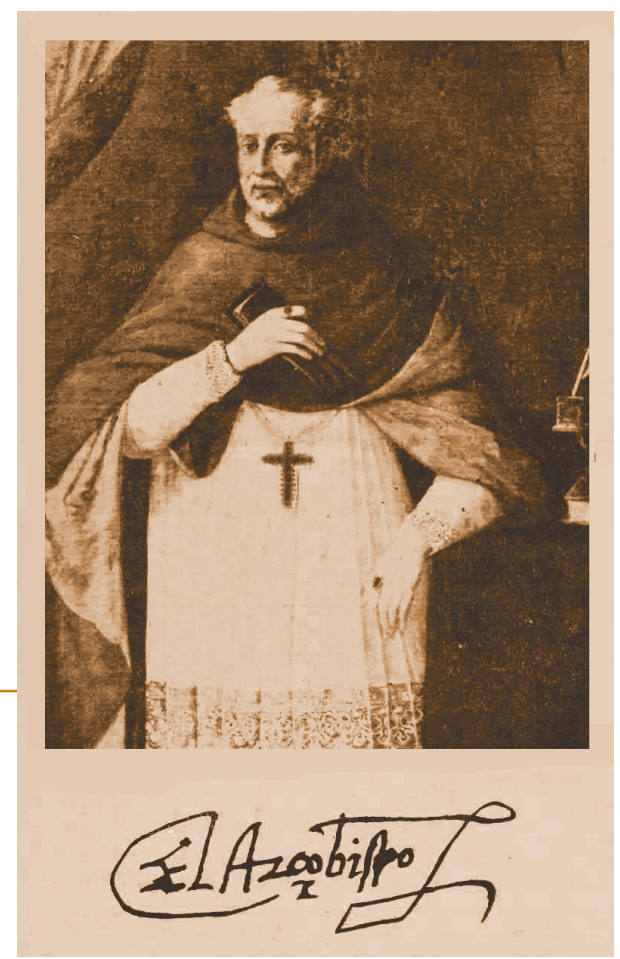

\section{LA LLEGADA DE LA IGLESIA SECULAR}

La llegada de Juan de Los Barrios a Santafé marcó el principio de lo que sería un largo y difícil proceso de transformación y desarrollo institucional para la Iglesia del Nuevo Reino de Granada, pero no su génesis en la región. Dos sacerdotes, el dominico fray Domingo de las Casas y el secular Antón de Lezcámez habían estado presentes en la expedición principal que culminó con la fundación de la ciudad española de Santafé en 1538 por Gonzalo Jiménez de Quesada (Mantilla, 1994, p. 9). Otros clérigos habían acompañado las expediciones lideradas por Federmán y Belalcázar. Se sabe poco acerca de estos religiosos o lo que hicieron, quizá por tratarse de una época tan temprana.

Inicialmente la ciudad de Santafé formó parte de la jurisdicción de la diócesis de Santa Marta. En enero de 1540 el Obispo envió como vicario general a Pedro García Matamoros al interior para que cumpliera las funciones de párroco en las recién fundadas ciudades de Santafé y Tunja (Lee, 1963, p. 9). A medida que la región atrajo más inmigrantes españoles y creció en importancia, también empezó a atraer la atención de las autoridades eclesiásticas. 
Martín de Calatayud, nombrado obispo de Santa Marta en marzo de 1542, se detuvo en Santafé en 1545 de camino a Lima, a donde se dirigía para su consagración. El obispo quedó convencido de la necesidad de regresar a la ciudad después de ser consagrado, pero murió antes de recibir notificación de dicho permiso (Pacheco, 1971, p. 168; Mantilla, 1994, p. 8). En esta autorización, una cédula de febrero de 1549, el rey reconocía que Santafé era un lugar más conveniente para que el obispo se asentara, "porque en ninguna parte de todo [el] obispado hay tanta gente como en el dicho Nuevo Reino ni donde tanto fruto se pueda hacer" (AGI, SF, 533, libro 1, 13r-13v). Aunque tardaría varios ańos para que un nuevo obispo llegara a Santa Marta, cuando Juan de Los Barrios arribó en abril de 1553 rápidamente empezó a preparar su viaje a Santafé. Fue así que el prelado llegó a residir en la capital del Nuevo Reino de Granada, aliviando a García Matamoros de sus funciones y empezando el arduo proceso de introducir al clero secular.

Para ese entonces, Santafé ya era la sede de la recién creada Audiencia, que gobernaba no solo la región de los Andes centrales -entonces conocida como el Nuevo Reino de Granada-, sino también las provincias de Cartagena y Santa Marta (Mayorga, 2013). La ciudad se estaba desarrollando rápidamente como capital administrativa y la corona pronto estuvo interesada en convertirla también en la capital eclesiástica de la región. Incluso antes de la llegada de Barrios a la ciudad en abril de 1553, el príncipe Felipe había solicitado al Papa que "la iglesia catedral de la provincia de Santa Marta y Nuevo Reino de Granada [...] que está erigida y fundada en la ciudad de Santa Marta, se mude y pase al dicho Nuevo Reino de Granada" (AGI, SF 552, lib. 1, 265r). La respuesta tardaría nueve años, pero cuando llegó como la bula In suprema dignitatis Apostolicae specula de Pío IV del 22 de marzo de 1564, no solo concedía el deseo del príncipe de trasladar la catedral a Santafé, sino también una petición más reciente para que se promoviera a arquidiócesis con las diócesis de Cartagena y Popayán como sus sufragáneas (Metzler y Roselli, 1991, pp. 733-739; Mantilla, 1994, pp. 25-32). En la teoría y en la legislación, el brazo secular de la Iglesia del Nuevo Reino se estaba desarrollando con rapidez, pero en la práctica las cosas eran algo más complicadas.

Cuando Barrios llegó a Santafé el clero secular -en la persona del vicario general García Matamoros y un puñado de sacerdotes- había estado administrando los sacramentos a la población española de la ciudad desde 1540, pero la evangelización de la población indígena se encontraba casi completamente en manos de las órdenes religiosas. Esta era una situación común a lo largo de la América española y en otros teatros misioneros de la época. Cuando la corona 
se vio frente a la necesidad de enviar mano de obra clerical a ultramar, solo las órdenes religiosas la podían proveer. Ellos tenían los números suficientes, de hecho sobrepasando a sus homólogos seculares en España en el siglo XVI; tenían además una larga tradición de actividad misionera dentro de Europa y en los más apartados límites del mundo conocido; y por encima de todo, eran los únicos en la Iglesia con la organización institucional que haría posible embarcarse en una empresa de este tipo (Van Oss, 1986, p. 4) . $^{2}$

Los clérigos diocesanos peninsulares no fueron disuadidos de viajar al Nuevo Mundo, pero en la práctica probablemente tenían obligaciones que los amarraban a parroquias y otros beneficios en Espańa y además estaban excluidos del programa de financiación sistemática a través del cual la corona española desplegó misioneros a lo largo del Nuevo Mundo. Entre 1493 y 1822 la corona envió a más de 15.000 sacerdotes regulares a destinos ubicados desde California hasta la Patagonia, incluidos 1.150 sacerdotes para el Nuevo Reino, que obtuvieron subsidio para cruzar el Atlántico y otros gastos de viaje (Borges Morán, 1977, pp. 477-540).

Simplemente por virtud de sus números, los regulares constituían la fuerza dominante en la Iglesia del naciente Nuevo Reino en la década de 1550. En 1553 ya había casi tres docenas de frailes en Santafé (Lee, 1963, p. 10, p. 30) y en el resto del siglo otros 500 dominicos, franciscanos y agustinos fueron despachados al Nuevo Reino ${ }^{3}$. En 1550, tanto los franciscanos como los dominicos llegaron a la ciudad con la intención de establecer conventos y ambas órdenes establecieron claustros en Tunja ese mismo año (Pacheco, 1971, pp. 305-306, p. 327). Los agustinos les siguieron en la década de 1570 (Pacheco, 1971, p. 340).

\section{LAS ÓRDENES RELIGIOSAS Y EL PATRONATO REGIO}

En términos legales, las órdenes religiosas pudieron participar en la evangelización del Nuevo Mundo debido a una serie de privilegios concedidos por el papado que les permitieron desempeñar funciones y ocupar cargos normalmente reservados para la jerarquía secular (Traslosheros, 2004, pp. 13-15; García, 1988). Estos privilegios tenían sus raíces en las misiones que realizaron las

\footnotetext{
${ }^{2}$ Para un bosquejo de las misiones regulares por fuera de Europa en el medioevo, véase Muldoon (1979).

${ }^{3}$ Claro está que estos números (de Borges, 1977, pp. 481-498) se refieren exclusivamente a los frailes enviados desde España a algún lugar del Nuevo Reino por la corona.
} 
órdenes mendicantes por fuera de Europa durante el medioevo y que fueron facilitadas por Roma (Muldoon, 1979). Las circunstancias habían cambiado desde, por ejemplo, la misión a China del franciscano Juan de Montecorvino en el siglo XIII, pero los privilegios de las órdenes religiosas seguían siendo bastante similares: permitían a los frailes desempeñar las funciones de párrocos en los lugares donde realizaban sus misiones y dotaban a sus superiores con poderes normalmente reservados a los obispos (Traslosheros, 2004, p. 14; Muldoon, 1979, pp. 65-66). Por ejemplo, en junio de 1521 el papa León X promulgó Alias felicis recordationis, que no solo autorizaba a los regulares a administrar los sacramentos del bautismo, la penitencia, la eucaristía y la extremaunción, sino que también concedía a las autoridades regulares, "en casos de necesidad, cuando no hay un obispo en la provincia" el poder de confirmar y ordenar hasta órdenes menores; consagrar capillas, altares y otros objetos e incluso nombrar sacerdotes a beneficios eclesiásticos (Metzler y Roselli, 1991, pp. 161-162).

$\mathrm{El}$ ańo siguiente estos privilegios fueron extendidos por la famosa bula $E x$ poni nobis fecisti de Adriano VI del 9 de mayo de 1522 (Metzler y Roselli, 1991, pp. 166-169). La bula, también conocida como Omnimoda, dotaba a "todos los mendicantes, especialmente los Franciscanos Observantes, de las dichas Indias, de nuestra autoridad" para poder hacer todo lo necesario para su misión donde no hubiera obispos, o donde el obispo más cercano estuviera a más de dos días de viaje, exceptuando actos que requirieran autorización episcopal (p. 166).

En 1525 este y otros privilegios franciscanos fueron explícitamente extendidos a los dominicos y en 1535, una bula de Pablo III eliminó el requisito de acudir al obispo si uno existía en un radio de dos días, siempre y cuando el obispo relevante lo permitiera ${ }^{4}$. Esta última concesión declaraba además que "la dicha autoridad sea extendida a todos los actos episcopales que no requieran haber recibido ordenación episcopal [qui Ordinem Episcopalem non requirunt]" (Metzler y Roselli, 1991, p. 307). En otras palabras, les permitía "realizar actos de gobierno, legislación y justicia que no requiriesen de la calidad sacramental inherente a los obispos" (Traslosheros, 2004, p. 14). De estos privilegios queda claro que las relaciones entre seculares y regulares en el Nuevo Mundo no serían claras: las concesiones en efecto hacían superflua a la figura del obispo en una amplia gama de circunstancias al dotar a los superiores regulares en conjunto, de poderes suficientes para dirigir la Iglesia y la evangelización en las regiones en las que realizaban su actividad misionera.

${ }^{4}$ Esto se hizo con las bulas Dum fructus uberes de Clemente VII de 1525 y Alias felicis recordationis Adrianos Papa VI de Pablo III de 1535. Véase García (1988, pp. 378-379). 
Los privilegios de las órdenes religiosas tenían el potencial de confinar al obispo al margen, a lo que fuera puramente sacramental, por lo cual en todo el Nuevo Mundo, la construcción e imposición de la jurisdicción episcopal implicaba necesariamente un conflicto con las órdenes religiosas ${ }^{5}$. Sería engañoso caracterizar la relación entre regulares y seculares en este periodo como una de conflicto y choque constante, pero la superposición y duplicación de sus funciones y jurisdicciones inevitablemente sentaban las bases para que existiera tensión y no en pequeña medida, debido a que las órdenes religiosas, con sus propias jerarquías, tradiciones, trayectorias e incluso métodos y prioridades en la evangelización, defendían sus privilegios ferozmente. Desde su perspectiva, la llegada de la jerarquía secular a Santafé necesariamente representaba, no solo una invasión de su monopolio sobre la evangelización de la población indígena, sino un desafío a su independencia.

En la práctica, el nuevo clero secular se vio obligado a buscar la cooperación y el apoyo de los regulares para cumplir con su objetivo de evangelizar a la población indígena. Esto lo tenía muy claro Juan de Los Barrios, quien se preocupó por hacer que su alianza funcionara. Una de sus primeras cartas a la corona, enviada incluso antes de su llegada a Santafé en abril de 1553, es reveladora en cuanto a su actitud general acerca de las órdenes religiosas (AGI, Patronato 197, r. 26, 123r-126r). Por un lado se quejaba de que los pocos sacerdotes que trabajaban entre la población indígena eran "las heces y escoria que España desecha por no poderlos sufrir", que "las órdenes que están fundadas" en el Nuevo Reino, franciscanos y dominicos, "todas están disipadas y destruidas", y que sus cabezas eran "enfermas y no las que debían [ser]" (124r).

De hecho, ambas órdenes estaban sufriendo dificultades, resultantes en parte de conflictos con las autoridades civiles y de disputas internas. Barrios estaba determinado a expulsar a "frailes renegados" de sus posiciones, incluso si quedaran "las iglesias desiertas y desamparadas" (125v). Pero al mismo tiempo, lo que Barrios quería era reformarlos, más que desplazarlos. El obispo sabía bien cuán problemática podía ser la falta de mano de obra clerical para el proyecto evangelizador. Como le explicó al rey en la misma carta de 1553, "la mayor necesidad que hay al presente en todas estas vuestras Indias y especialmente en estas iglesias del Nuevo Reino es de ministros, así de clérigos como de frailes" (125v). En prácticamente todas sus cartas a la

\footnotetext{
${ }^{5}$ Sobre este proceso en la Nueva España, véase Traslosheros (2004, p. 15 y siguientes).
} 
corona entre su llegada y su muerte en 1569, el prelado continuó solicitando que enviaran más frailes al Nuevo Reino, aunque más disciplinados y mejor entrenados (Lee, 1963, p. 16).

Esto cambiaría más adelante con las reformas introducidas después de la conclusión del Concilio de Trento y un renovado deseo por parte de la corona española de desempeñar un papel más activo en el gobierno de la Iglesia y su programa evangelizador, algo que se intentó conseguir a través del fortalecimiento del poder de los obispos. En el Nuevo Reino esto resultó en un conflicto amargo entre regulares y seculares, el cual culminó tan solo durante el arzobispado siguiente. Pero por el momento, la prioridad de Barrios continuó siendo atraer frailes a su Arquidiócesis y cerciorarse de que efectivamente se dedicaran a la evangelización de la población indígena de manera adecuada.

Hubo otro grupo con el que Barrios tuvo que lidiar: las autoridades civiles. Esto fue el resultado de la serie de privilegios y poderes que el papado había concedido a sucesivos monarcas españoles desde el final del siglo XV, lo que llegó a conocerse como el patronato regio sobre la Iglesia (Muldoon, 1979). Dichas concesiones se basaron en aquellas dadas anteriormente a los monarcas portugueses para sus expediciones de exploración y conquista en ultramar.

En 1455 por ejemplo, la bula Romanus Pontifex de Nicolás V le concedió a los monarcas portugueses el poder de fundar iglesias, monasterios y otras instituciones religiosas en territorios recién conquistados, y de "enviar a ellas cualquier género de persona eclesiástica, [...] tanto seculares como regulares de cualquiera de las órdenes mendicantes" y autorizaba que los misioneros residieran en los lugares a los cuales fueran enviados de manera permanente y que administraran allí los sacramentos ${ }^{6}$. En otras palabras, la bula efectivamente pasaba las riendas del proyecto misionero a la corona portuguesa. Muy pronto, como es de esperarse, los monarcas castellanos empezaron a pedir al papado concesiones similares y Alejandro VI respondió a sus peticiones en 1493 con tres bulas: dos con el íncipit Inter caetera, el 3 y 4 de mayo de 1493 y una tercera, Eximiae devotionis del 3 de mayo ${ }^{7}$.

${ }^{6}$ El texto de Romanus Pontifex está recopilado en Davenport y Paullin (1917, p. 24). Esta y todas las otras traducciones son mías, a menos que se especifique lo contrario.

${ }^{7}$ Véase Muldoon (1979, pp. 137-140) y Figuera (1965, p. 22). Los textos de las tres bulas están recopilados en Metzler y Roselli (1991, pp. 71-75, 75-78, y 79-83 respectivamente). 
Siguiendo el formato de Romanus Pontifex, las dos bulas Inter caetera le concedían a la corona española el monopolio sobre la evangelización en la esfera de influencia que le correspondía. La tercera bula extendía a la monarquía espańola los privilegios que Roma había concedido a la corona portuguesa (Metzler y Roselli, 1991, p. 77; Sánchez Bella, 1991, p. 20). Se concedieron privilegios adicionales en los ańos siguientes, incluida la bula Eximiae devotionis sinceritas de 1501, que le entregaba todos los diezmos de las Indias en perpetuidad, a cambio de la obligación de proveer los recursos necesarios para satisfacer las necesidades de la Iglesia y Ellis fluciti praesidio de 1504, que autorizaba a los monarcas españoles a erigir obispados ${ }^{8}$. Las concesiones culminaron con la bula Universalis Ecclesiae Regiminis del 28 de junio de 1508, que le conferían el patronato universal a la corona española sobre todas las iglesias de las Indias, incluido el derecho exclusivo de fundar instituciones eclesiásticas y presentar candidatos a todos los beneficios eclesiásticos?

De esta manera, cuando Barrios llegó a la ciudad de Santafé los privilegios concedidos a la corona española eran tales que no solo existía un grado adicional de separación entre la Iglesia del Nuevo Mundo y Roma, sino que en efecto, tanto la jerarquía civil como la eclesiástica respondían a la corona. Esto quería decir que el presidente y los oidores que conformaban la Real Audiencia ejercían algunos de estos poderes en representación del monarca. Por esta razón como resalta Jorge Traslosheros, es anacrónico hablar de conflictos entre "la Iglesia y el Estado", pues esta era una época en la cual tal división ni siquiera era concebible: "sólo es posible hablar de la potestad eclesiástica y la potestad secular del monarca hispano en las Indias Occidentales, entre las cuales hubo problemas" (2004, p. 71).

El problema una vez más surgía porque los límites entre las jurisdicciones de las autoridades civiles y eclesiásticas de la región no estaban ni claros ni fijos. Instancias de conflicto y su eventual resolución sentaban precedentes que ayudaban a definir estos límites de manera más precisa, aunque estos siempre seguían susceptibles a cambiar y a ser cuestionados a medida que las circunstancias iban evolucionando. Y ya que la evangelización de la población indígena era una materia del Estado y la función fundamental de la Iglesia en la región, es de esperarse que siempre tuviese el potencial de convertirse en una fuente de tensión.

${ }^{8}$ Eximiae devotionis sinceritas del 16 de noviembre de 1501 y Illus fulciti praesidio del 15 de noviembre de 1504, en Metzler y Roselli (1991, pp. 89-91 y 91-94, respectivamente).

${ }^{9}$ Universalis Ecclesiae Regiminis de 28 del junio de 1508, en Metzler y Roselli (1991, pp. 104-107). Véase también Sánchez (1991, p. 23) y Sá (2007, p. 257). 


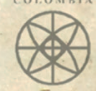



Una ilustración contemporánea del poder que tenían las autoridades civiles sobre materias eclesiásticas se puede ver claramente en una de las primeras directivas que se expidieron sobre la evangelización de la población indígena en la región. Estas fueron ordenanzas promulgadas, no por Juan de Los Barrios o su predecesor, sino por Juan de Maldonado, el fiscal de la Audiencia, más de un año antes de que el sínodo de Barrios de 1556 publicara sus constituciones (AGI, Patronato 197, ramo 27, 127r-130v). Dichas ordenanzas se expidieron para Cartagena con la participación de las autoridades seculares y regulares de la región en un momento en el cual el obispo de la ciudad se había ausentado para viajar a Roma para renunciar a su obispado (Pacheco, 1971, pp. 160-161). A través de Maldonado y en representación del monarca, la Real Audiencia intervino para asegurarse que se publicara la legislación que Cartagena requería en ese momento. Pero, ¿qué pasaba si había un desacuerdo entre los regulares, las autoridades civiles y el obispo? Si las relaciones eran menos armónicas, como lo fueron en varias ocasiones, esta duplicación de funciones podía ser realmente desastrosa.

En términos básicos, el poder del obispo era doble: la potestad sacramental conferida por su ordenación episcopal, que le permitía por ejemplo, ordenar candidatos al sacerdocio o consagrar el crisma; y una potestad jurisdiccional que le permitía legislar y administrar la justicia y en general, gobernar los asuntos eclesiásticos de su diócesis (Traslosheros, 2004, pp. 1-2). La primera era inherente a la condición del obispo, conferida con su ordenación, pero la segunda -dadas las concesiones hechas a las órdenes religiosas y a la corona espańola en el Nuevo Mundo, así como a los limitados recursos del nuevo obispo- era menos sencilla. La llegada del clero secular implicaba una afirmación por parte de sucesivos obispos de su potestad jurisdiccional. En términos prácticos, esto hacía necesaria la construcción de un marco legal e institucional. El sínodo de 1556 fue un primer paso en ambos sentidos: fue una afirmación del poder del obispo sobre su diócesis y al mismo tiempo, una serie de directivas prácticas para su gobierno cotidiano y su desarrollo institucional a futuro.

El sínodo no fue estrictamente la única legislación que gobernaba a la diócesis en ese momento. Su documento fundacional, la erección, ya había establecido los aspectos más básicos del funcionamiento del nivel más alto del gobierno del clero secular: constituía el capítulo catedral, regulaba su composición y las diferentes funciones de sus miembros, decretaba cómo se distribuirían los diezmos y trataba otros temas internos de este tipo ${ }^{10}$. Pero el sínodo de

\footnotetext{
${ }^{10}$ Para más detalles sobre este documento, el cual había sido preparado por Barrios incluso antes de su nombramiento a esta diócesis, como obispo de Asunción, véase Mantilla (1994), p. 17 y ss.
} 
1556 constituyó la primera vez que este gobierno del clero secular afirmó su posición de liderazgo sobre la Iglesia del Nuevo Reino, por lo menos en papel.

\section{EL SÍNODO DIOCESANO DE 1556}

Como el primer corpus legislativo promulgado para gobernar toda la diócesis, el sínodo de 1556 trataba una amplia variedad de materias pertinentes a su administración y al gobierno de sus instituciones. Sus constituciones también incluían una serie de directivas fundamentales concernientes a la evangelización de la población indígena, directivas que son muy reveladoras de las preocupaciones y prioridades de la evangelización de este periodo inicial. El sínodo basó gran parte de su legislación en las constituciones de los concilios provinciales de Sevilla de 1512, Lima de 1551 y México de 1555, y la mayoría de sus directivas de hecho no fueron muy distintas a las del concilio sevillano (Romero, 1960, p. 459). Uno de los pocos cambios frente a este último, tomado de las constituciones del Primer Concilio Limense, fue requerir a los confesores que pidieran a sus feligreses indígenas que recitaran lo que el sínodo requería que aprendieran antes de darles la absolución, un cambio que respondía al nuevo contexto misionero (Constituciones, 1556, p. 463).

En términos prácticos, la legislación repetía las directivas de la corona que requerían a los encomenderos hacer provisión adecuada para la evangelización de los grupos bajo su jurisdicción, proveyendo un sacerdote para que catequizara, o -a falta de dinero suficiente y una población numerosa para justificarlocatequizar ellos mismos (Constituciones, 1556, p. 465). En asentamientos más grandes donde residieran caciques, se debía construir una iglesia. En lugares más pequeños, se requería que por lo menos "se señale un lugar decente en que se ponga una Cruz para que allí se les diga la doctrina cristiana” (p. 465). En todas las doctrinas de la diócesis las campanas debían tañer todos los domingos y festivos para congregar a la población indígena para su instrucción religiosa y "en cada ciudad" se debía seleccionar "dos alguaciles de los más cristianos indios y más ladinos", para que se cercioraran de que todos los habitantes indígenas cumplieran con sus obligaciones, yendo "de casa en casa" con el poder de multar a los que no lo hicieran, con el incentivo de quedarse con la mitad de la multa (p. 463) ${ }^{11}$.

${ }^{11}$ Esto repetía los requisitos de la legislación de los concilios de Lima y México de la década de 1550, aunque de manera mucho más modesta. Sobre asistentes indígenas bajo las reglas del I Concilio Limense, véase Charles (2010, p. 19). 
Está claro que estos requisitos eran bastante limitados y reflejaban cuán precarios eran los recursos a la disposición del clero secular en la década de 1550. Este no podía hacer mucho más que legislar para establecer el nivel más básico de instrucción religiosa que debía recibir la población indígena. Incluso si estas provisiones incluían penas y multas para los que las ignoraran, tanto entre la población indígena como entre quienes tenían la responsabilidad de evangelizarlos, en la práctica había muy poco que la Iglesia pudiera hacer para que se cumplieran sus directivas. De hecho, ni siquiera podía vigilar el uso de textos litúrgicos entre sus propios sacerdotes y tuvo que permitir la utilización de una variedad de textos, incluido el Misal Romano pretridentino, el misal sevillano, o el mexicano (Constituciones, 1556, p. 468). En otras palabras, aunque la situación que la legislación sinodal de 1556 reflejaba era algo más sofisticada que lo que presentaba aquella de los primeros años de evangelización en América -cuando las circunstancias habían obligado a la corona a delegar la mayor parte de la responsabilidad de evangelizar a la población indígena a encomenderos y frailes, como en las Leyes de Burgos-Valladolid de 1512-1513 (AGI, IG 419, lib. 4, 83 r-96v) - aún había mucho camino por recorrer. Pero ahora por lo menos existía en papel una serie de directivas para la conducta de la evangelización en Santafé. Y lo que es aún más interesante, estas directivas contenían una declaración de lo que esta instrucción religiosa debería comprender.

Para ser cristianos, la población indígena debía aprender lo que el sínodo consideraba los puntos básicos de la religión cristiana: primero cómo santiguarse, luego "que han de creer en la Santísima Trinidad [...] y los catorce artículos de la Fe: y los diez mandamientos de la Ley de Dios" (Constituciones, 1556, pp. 461-462). También debían conocer los siete pecados capitales, las virtudes teológicas y cardenales, las obras de misericordia, los dones del Espíritu Santo, el acto de contrición y las oraciones básicas: el Padre Nuestro, el Ave María, el Salve Regina y el Credo (p. 461). Estos puntos básicos debían ser enseñados en castellano, "porque mejor los puedan entender y aprender" (p. 461), al menos comparado con aprenderlos en Latín. Y esta información debía ser escrita y exhibida en algún lugar donde todos la pudieran ver, si es que sabían leer (p. 462). Más adelante, siguiendo el texto del I Concilio Limense, las constituciones intentaron introducir algún grado de homogeneidad en el contenido de la catequesis, requiriendo que los misioneros cubrieran algunos temas esenciales. La instrucción debía empezar con la idea cristiana del alma: 
[...] la diferencia que hay entre nosotros los hombres, y los demás animales, que cuando ellos mueren, mueren cuerpo y alma, y todo se vuelvetierra; peroloshombres no: quesóloel cuerpo muere, maselalma nunca muere, sino vive para siempre (Constituciones, 1556, p. 477).

Pero no todas las almas inmortales, claro, tendrían la misma suerte pues "los señalados por el Santo Bautismo, guardando lo que Dios manda van con Él a gozarle en el Cielo [...] y a esto llamamos gloria, y bienaventuranza" (p. 477). Para que estas ideas quedaran aun más claras, el texto exhortaba a los predicadores a que explicaran a sus catecúmenos indígenas que "como todos sus antepasados que no fueron Cristianos, ni conocieron a Dios, ni le adoraron, ni sirvieron, sino a las criaturas, como el Sol, y la Luna, piedras e ídolos están ahora atormentados" (pp. 477-478). Los misioneros luego debían ofrecer a sus oyentes una alternativa a este camino hacia la perdición, contándoles acerca de la existencia de la Trinidad, la historia cristiana de la Creación en detalle, la Caída, la Encarnación, la Pasión de Cristo y su Resurrección, y el significado de todas estas cosas para ellos (pp. 478-480); todo esto haciendo énfasis en que el conocimiento de estos misterios les ofrecería la posibilidad de evitar el tormento eterno.

El texto luego pasaba a condenar la apelación a deidades no cristianas, y el peligro y futilidad de adorar "al sol y la luna, [...] estrellas, [...] a las piedras, ídolos [y] tunjos" (Constituciones, 1556, p. 474). Denunciaba también a "los hechiceros que llaman Xeques o Mohanes" y establecía penalidades para quienes concertaran con ellos (p. 474). Además, ordenaba que objetos y edificios indígenas sagrados fueran destruidos (p. 465). Todos los indios, bautizados o no, que se hallaran participando en "ritos y ceremonias antiguas en borracheras y bailes supersticiosos" debían ser capturados y castigados (p. 469).

Desde luego, nada de esto era nuevo o único al Nuevo Reino. De hecho, no está claro cuántas de estas supuestas manifestaciones de religión indígena, que están contenidas en este y otros textos contemporáneos, reflejaban la realidad y cuántas eran más bien el reflejo de las expectativas de los españoles - expectativas derivadas de su experiencia en otros lugares de América, de la historia y teología cristiana y de fuentes bíblicas- o incluso de las categorías que los españoles utilizaron (consciente o inconscientemente) para entender e interpretar lo que estaban encontrando ${ }^{12}$.

${ }^{12}$ Véase MacCormack (1991, p. 36 y ss.) sobre la manera en que ya hacia el final del siglo XV había surgido en la teología cristiana, una retórica de yuxtaposición sistemática entre doctrina verdadera y doctrina falsa, expresada en términos de doctrina de Dios y doctrina del diablo. 
En cualquier caso, la lógica del sínodo quedaba clara: no era necesario solamente "hacer Iglesias y Templos, donde Dios nuestro Señor sea honrado y servido", sino también "deshacer las que están hechas en honra y culto del demonio" (Constituciones, 1556, p. 465).

Sin embargo, a pesar de todo el énfasis que hacía el sínodo sobre la importancia de una catequesis adecuada y de eliminar distracciones e influencias malignas para facilitarla, las constituciones no permiten a la población indígena participar enteramente en la vida religiosa cristiana. Esto es especialmente claro en la prohibición que hace el sínodo de su participación en la comunión. El bautismo era imprescindible, el matrimonio era una necesidad práctica y la confesión era deseable, incluso si en la práctica los obstáculos lingüísticos la hacían imposible. "Pero el sacramento de la Eucaristía mandamos al presente que en ninguna manera se les administre, salvo si fuere alguna casada con Español" y entonces solo con el mayor cuidado y preparación (Constituciones, 1556, p. 470). Incluso, cuando el sínodo discutió el tema de aquellos cercanos a la muerte, ni siquiera mencionó el viático (p. 466).

El sínodo no explica por qué no se debía admitir a la población indígena en la Eucaristía, pero el hecho de que el texto exima de esta restricción a las esposas indígenas de los españoles es revelador. Lo que está en juego es la idea de la madurez espiritual, de si el individuo que recibe el sacramento es capaz de apreciar su significado y si es idóneo. La misma preocupación es evidente en las constantes admoniciones que hacen a los sacerdotes de preparar adecuadamente a los catecúmenos adultos antes de bautizarlos para evitar la posibilidad de que, al no entender la importancia de lo que se les estaba concediendo, retornaran a sus ideas y prácticas antiguas. De hecho, la participación en prácticas no cristianas luego del bautismo sería aún más dañina.

La lógica que sustentaba esta ansiedad es importante: la participación completa en el cristianismo requiere madurez espiritual y esta madurez resulta del aprendizaje y aceptación de los principios básicos de la doctrina cristiana y de la abstención de prácticas incompatibles con ella. Hasta que maduraran, administrar la Eucaristía sería irresponsable ${ }^{13}$. Esto concordaba con lo que había decretado el I Concilio Limense al principio de la década: la población indígena no debía admitir el sacramento "hasta que estén más instruidos y arraigados en la fe y conozcan mejor los misterios y sacramentos".

${ }^{13}$ Sobre debates acerca de la admisión de la población indígena a la Eucaristía, véase Pardo (2004, p. 136 y ss.). 
Hasta entonces, solo sería permisible su admisión a "los sacramentos del baptismo, penitencia y matrimonio" (Vargas, 1951, pp. 14-15).

De esta manera, la lógica de 1556 era simple: la población indígena debía aprender los principios de la fe cristiana y ser bautizados, luego debían mantenerse alejados de prácticas e ideas incompatibles con la nueva religión. Su conversión total y final llegaría -según proponía el sínodo- a medida que su cristiandad madurara, pero mientras tanto sería necesario excluirlos de incluso algunos de los aspectos más centrales de la vida religiosa católica. Esta lógica que sostenía la legislación de 1556, era el resultado de una coyuntura ideológica, resultado de la intersección de dos influencias relacionadas. La primera: el surgimiento de una caracterización muy particular de la población indígena; la segunda: la influencia de las ideas y prioridades de la llamada Prerreforma española, el movimiento de renovación y reforma religiosa supervisado y avanzado por los Reyes Católicos y su arzobispo de Toledo, Francisco Jiménez de Cisneros.

\section{LA COYUNTURA IDEOLÓGICA DE LA EVANGELIZACIÓN}

En la América Española la conceptualización de la población indígena tomó una forma muy distintiva a través del surgimiento de lo que Alejandro Cañeque y otros han llamado la "retórica de miserableza", la cual vino a dominar la perspectiva que tenían las autoridades de esta población y a justificar y definir la misión civilizadora del proyecto colonizador español (Cañeque, 2004; Estenssoro, 2003; Pardo, 2004). En esta caracterización el amerindio se convierte en una persona miserable, por naturaleza débil y corruptible, que necesita ser protegida y orientada ${ }^{14}$. Son los primeros misioneros quienes exponen dicha representación, especialmente los franciscanos, para justificar su presencia y recordar a la corona sus obligaciones con sus nuevos súbditos (Castañeda, 1971, pp. 245-258). Pero en el transcurso del siglo XVI, esto llegó a ser una parte fundamental del discurso de autojustificación de todo el proyecto colonial.

Un ejemplo claro de estas ideas se puede encontrar en los escritos del influyente franciscano Gerónimo de Mendieta, activo en la Nueva Espańa, que en un memorial al rey de 1587, propuso que la población indígena era "la gente más pobre, más débil y flaca, más ignorante y más descuidada que

${ }^{14}$ Para Cañeque (2004, p. 187) “la idea del nativo como 'persona miserable' es el elemento que define el discurso sobre el indio de la corona española”. 
ninguna otra nación" (García, 1892, p. 7). Por este motivo, eran "mansos, domésticos y pacíficos [...] despreciados de sí mismos, obedientes y de increíble paciencia" (p. 11). Pero por la misma razón, eran susceptibles a la corrupción y necesitaban ser corregidos: "les es tanto menester el azote [...] que en faltándoles el azote como niños son perdidos" (p. 9). Esta comparación es fundamental, pues la conceptualización que estaba surgiendo los infantilizaba.

En círculos intelectuales, los debates iniciales acerca de la naturaleza y humanidad de los indios pronto fueron reemplazados por aquellos que desarrollaron y racionalizaron la infantilización por parte de Vitoria y la Escuela Salmantina (Hanke, 1974, p. 160). Basándose en nociones aristotélicas de esclavitud natural, juristas y teólogos arribaron a la posición de que los amerindios eran humanos y tenían la capacidad de usar la razón, pero que este uso de razón no estaba aún completamente desarrollado. Puede que no fueran esclavos naturales, pero sí niños naturales ${ }^{15}$. En sentido religioso, dicho estatus de la población indígena se expresó en términos de madurez espiritual.

Estas ideas fueron influyentes. Para Mendieta por ejemplo, tras la conquista española "quedaron en el estado, capacidad y talento como de los muchachos como de nueve o diez años, necesitados de ser regidos por tutores o curadores" (García, 1892, pp. 28-29). Dichos custodios eran desde luego, el monarca español y sus funcionarios civiles y eclesiásticos en el Nuevo Mundo. Más aún, este tutelaje se convirtió en la justificación del régimen colonial: la lógica original detrás del título de España al nuevo mundo era la necesidad de introducir el cristianismo, pero con el tiempo pasó a ser el mantenimiento de la ortodoxia cristiana y de la policía. Muy pronto, el tutelaje y supervisión de la población indígena por parte de la corona española y sus funcionarios llegó a pensarse como un proyecto interminable, en peligro constante de reversión ${ }^{16}$. A medida que se desarrolló la idea del Indio conforme progresaba el siglo, su falta de madurez espiritual se concibió como algo inherente a su condición y por ende permanente ${ }^{17}$.

${ }^{15}$ En la redefinición teorética del amerindio de esclavo natural a niño natural, véase Pagden (1982, pp. 104-108) y Muldoon (1979, p. 150 y siguientes).

${ }^{16}$ Véase Estenssoro (2003, p. 144 y siguientes). Para Pagden (1982, p. 105), "siempre y cuando (...) los indios permanecieran como nińos, los espańoles tenían la obligación de permanecer a cargo de ellos".

${ }^{17}$ Para Juan Carlos Estenssoro (2003, p. 142), “de haber considerado la evangelización como un hecho consumado, hubiese corrido el riesgo de tener que abolir el nombre de indio, debiéndolo reemplazar simplemente por el de cristiano, y, en consecuencia, poner punto final a la situación colonial”. Véase también Estenssoro (2001, p. 457). 
En cualquier caso -dejando a un lado la manera en que se desarrollaron estas ideas en los años siguientes-, las constituciones de 1556, al plantear la necesidad de proveer a los débiles indios la supervisión y el tutelaje adecuados, ya evidenciaban la influencia de ese paternalismo. Como en el resto de la América española, la teología de los sacramentos representaba un camino de desarrollo espiritual a través de la conquista de varios hitos significativos. Sin embargo, en el caso de la población indígena se resaltaba lo incompleta y condicional que era su incorporación en el cristianismo. Esta posición también se apoyaba sobre otros cimientos intelectuales y teológicos: la influencia de las ideas de Erasmo y del Humanismo en una parte del clero de la península ibérica en las primeras décadas del siglo XVI durante la llamada Prerreforma española.

El supuesto éxito y eficacia del movimiento de reforma eclesiástica de los Reyes Católicos, que no se cuestionó por mucho tiempo, ha sido tratado de manera más crítica en décadas más recientes ${ }^{18}$. Puede que sus efectos prácticos se hayan limitado en alguna medida a la reforma de las órdenes religiosas y los niveles más altos del clero secular ${ }^{19}$. Pero una consecuencia del movimiento y de las influencias que lo motivaron -el humanismo y el erasmismo-, fue una renovada hostilidad hacia la heterodoxia religiosa por parte de las autoridades eclesiásticas: a prácticas entre los laicos que las autoridades consideraban supersticiosas y a tradiciones locales y prácticas sincréticas que habían sido toleradas por la Iglesia medieval (Nalle, 1992, p. 30). El resultado no solo fue un esfuerzo por eliminar entre el feligresado este tipo de prácticas que las autoridades consideraban incompatibles con su visión más educada de la doctrina cristiana, sino más fundamentalmente, un intento por eliminar oportunidades en las que pudieran surgir errores.

El propio Erasmo había resaltado cómo muchas de las manifestaciones de creencias y devociones cristianas, como las "ceremonias externas de los cristianos y las devociones de los simples, especialmente aquellas que han sido aprobadas por la autoridad de la iglesia" (Erasmo, 1988, p. 73), podían ser malentendidas y resultar contraproducentes. El problema era que tenían también el potencial de generar errores, una propensión a distraer a los fieles de tal manera que ado-

${ }^{18}$ Tan temprano como en el estudio de Bataillon (1966, p. 1), que criticó su caracterización como un éxito por la Generación del 98. Esta última posición luego fue reiterada en términos más generales por Elliott (1963, p. 105) y criticada por investigadores como Kamen (1993, p. 48) y Nalle (1992, p. xiii, 24, 207), entre otros.

${ }^{19}$ Esta es precisamente la posición de Nalle (1992, p. xiii), para quien "las políticas de los Reyes Católicos principalmente afectaron los niveles más altos de la iglesia y las órdenes religiosas". 
raran a Dios "a través de las cosas visibles por el bien de las cosas visibles, y convencerse de que esto [el participar en lo externo] es la cumbre de la perfección religiosa” (p. 73), un peligro al que eran especialmente susceptibles las personas sin educación y aquellos nuevos a la fe $\mathrm{f}^{20}$. Y si este era el caso en Europa, más lo sería en el Nuevo Mundo, donde lo que no era familiar tendía a interpretarse en términos de error y donde tantas cosas eran extrañas que parecían apuntar hacia el diablo y la fuerza de su influencia sobre la región y sus habitantes indígenas (MacCormack, 1991, pp. 4 y siguientes, 52-55).

Estas ideas tuvieron una influencia profunda sobre la forma que tomó el catolicismo exportado a América por parte de los misioneros de las órdenes religiosas, el sector de la Iglesia española entre el que los esfuerzos de reforma de los Reyes Católicos tuvieron el mayor impacto ${ }^{21}$. El cristianismo de la España del siglo XVI no era ni homogéneo ni uniforme, sino más bien caracterizado por variaciones resultantes de la historia y de las costumbres de las distintas localidades. En su estudio de la religión de Castilla la Nueva en este periodo, William Christian resaltó cómo "en las aldeas, pueblos y ciudades de España central", y de hecho el resto de la Europa católica, "había dos niveles de catolicismo" (1981, p. 3). Uno era "el de la Iglesia Universal, basado en los sacramentos, la liturgia romana y el calendario Romano". El segundo, "uno local, basado en espacios sagrados particulares, imágenes, reliquias, santos patrones elegidos a nivel local, ceremonias idiosincráticas y un calendario único construido a lo largo de la historia particular de cada asentamiento" (p. 4).

Sin embargo, este nivel inferior de vida y experiencia religiosa está casi completamente ausente en las constituciones del sínodo de 1556 que conciernen a la población indígena. No hay ningún esfuerzo por ejemplo, por involucrar a la población indígena en cofradías o hermandades religiosas, en devociones a santos, al culto de imágenes sagradas o muchos de los otros aspectos importantes de la vida católica cotidiana en la Europa del siglo XVI. Este tipo de cosas tendrían que esperar: incluso la admisión de la población indígena a la Eucaristía se pensaba irresponsable.

De hecho, al intentar exportar un cristianismo homogéneo y uniforme, lo que los misioneros trataron de introducir en el Nuevo Reino fue una versión del

${ }^{20}$ Esta cita, del Enchiridion militis Christiani de Erasmo de 1503 (1988) fue analizada por Batallion (1996, p. 200). La traducción es mía.

${ }^{21}$ Algunos de los cuales, como los franciscanos, en sus primeras misiones en el Nuevo Mundo, habían entendido su proyecto además dentro de un marco milenarista. Véase Phelan (1970). 
catolicismo diseñada con la intención de limitar las ocasiones en las que se pudieran generar errores entre los neófitos. En otras palabras, fue el catolicismo de los reformadores españoles, de la reacción humanista y erasmista en contra de la "superstición", de reformadores para quien "la religión del feligresado [español] era ignorante, pagana y laxa”, para quien ese segundo nivel de la experiencia religiosa era poco fiable (Christian, 1981, p. 4). En el Nuevo Mundo, donde además existían preocupaciones acerca de la influencia maligna de las prácticas indígenas y cada vez más acerca de la poca confiabilidad de los mismos amerindios, ¿para qué introducir elementos potencialmente problemáticos? ¿Para qué eliminar una serie de supersticiones y errores, y luego introducir otra?

$\mathrm{Al}$ mismo tiempo, otro problema relacionado -también resaltado por el mismo Erasmo- era que las críticas de los reformadores a prácticas cristianas pero supuestamente supersticiosas, podían ser malinterpretadas por los más ignorantes o los neófitos, quienes probablemente no entenderían el sutil razonamiento de los reformadores (Erasmo, 1988, p. 73). En el Nuevo Mundo por lo tanto, quizás era mejor no introducir este tipo de prácticas desde el principio y así evitarse todos estos problemas del todo.

Estos eran los cimientos ideológicos del clero secular del Nuevo Reino de Granada y estuvieron claramente reflejados en la legislación de su sínodo fundacional de 1556. Institucionalmente, la Iglesia estaba progresando, a pesar de que había mucho camino aún por recorrer. Pero a nivel ideológico, como el resultado de una coyuntura de influencias teológicas e intelectuales, la evangelización se limitó en gran medida a la catequización, a la enseñanza de un puñado de oraciones y de los puntos más básicos de la doctrina cristiana, pero aun reservando aspectos fundamentales de la vida religiosa católica del siglo XVI y excluyendo a la población indígena del sacramento central de la Iglesia. Las cosas empezarían a cambiar rápidamente, pero solo en uno de estos niveles. Ambos merecen más atención.

\section{LA CONSTRUCCIÓN DE LA IGLESIA}

En lo institucional, a pesar de la afirmación por parte de Barrios de su potestad jurisdiccional como obispo con el sínodo de 1556 y el estilo grandilocuente de sus constituciones, la realidad era muy distinta. Esto le quedó dolorosamente claro apenas intentó implementar, incluso las muy limitadas directivas del sínodo que concernían a la evangelización de la población indígena. El sínodo había reiterado la obligación que tenían los encomenderos de proveer lo necesario 


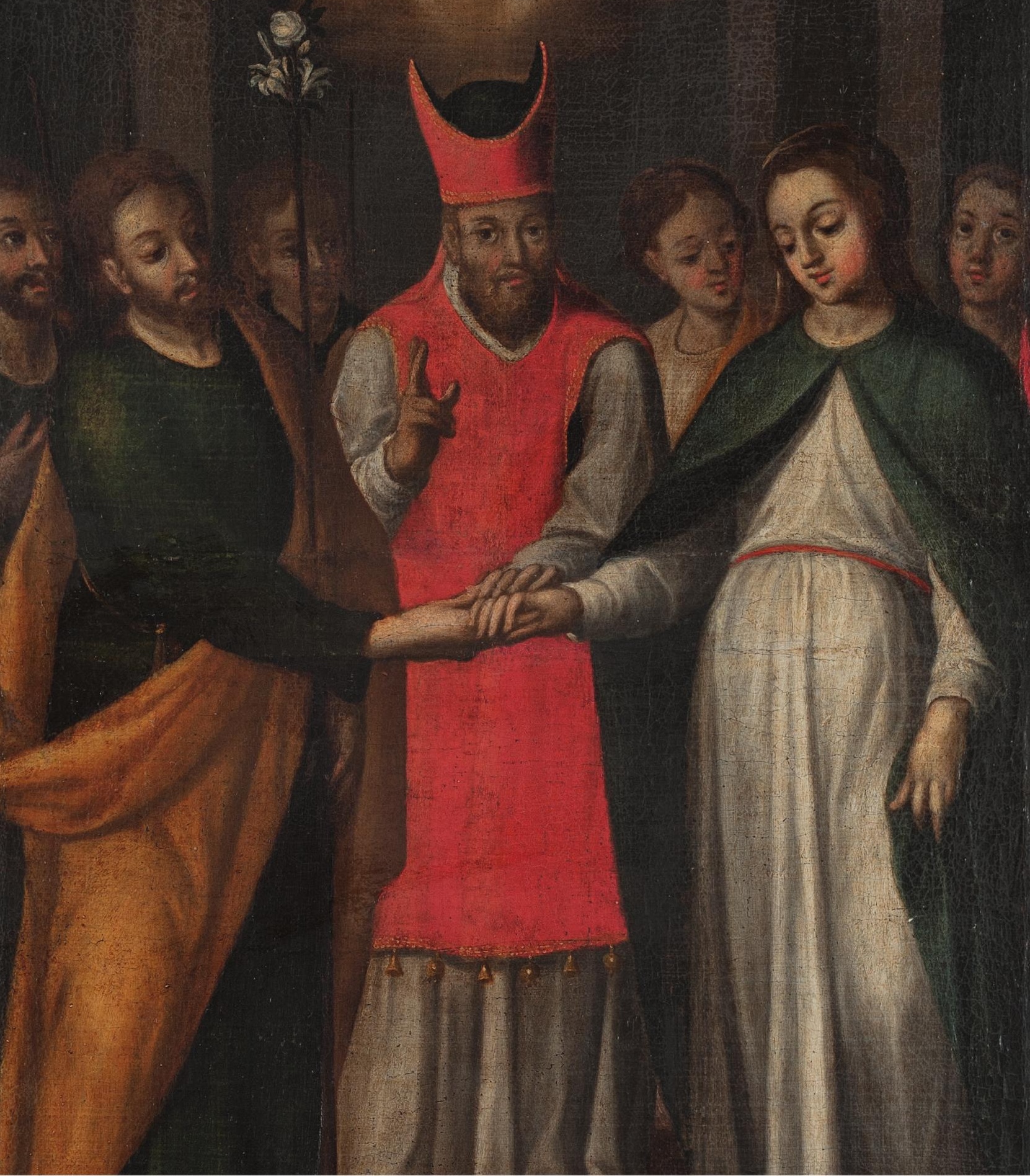

Figura 3. Anónimo. (Siglo XVII). Desposorios de la Virgen. En: Edison Sahamuel Ortiz., Pbro. (Dir.) (2012),ArteSacro 450años Arquidiócesisde Bogotá. Bogotá: Consuelo Mendoza Ediciones. p. 80. 
para la evangelización de los grupos bajo su poder y de devolverles la propiedad que les habían quitado ilegalmente, como por ejemplo en el cobro de tributos que excedían lo prescrito por la ley (Constituciones, 1556, pp. 555-558).

Barrios intentó imponer penalidades y censuras eclesiásticas para cerciorarse que los encomenderos obedecieran lo que dictaban las constituciones, pero sin mucho éxito. Con el apoyo del cabildo de la ciudad de Santafé, los afectados se quejaron ante la Real Audiencia, la cual intervino a su favor y ordenó al obispo que levantara todas las censuras que había impuesto (Zamora, 1945, pp. 69-70). Cuando Barrios intentó viajar a España para obtener el apoyo del rey, la Audiencia le impidió salir del Nuevo Reino. Incluso sus cartas a la corona no obtuvieron el resultado deseado: en marzo de 1561, la Audiencia logró obtener una cédula que ordenaba que ninguna de las constituciones sinodales o conciliares fueran publicadas o impresas sin la autorización previa del Consejo de Indias y que dotaba a las audiencias reales de los distintos territorios con el poder de suspenderlas si consideraban que afectaba los poderes y la jurisdicción del real patronato sobre la Iglesia ${ }^{22}$.

En otras palabras, la Real Audiencia también estaba tratando de reclamar el liderazgo de la Iglesia a través de los aún nebulosos poderes del patronato regio que ejercía en representación del monarca. Esto también es bastante claro, por ejemplo en los eventos que rodearon un famoso incidente que ocurrió en el pueblo de Ubaque en la Nochebuena de 1563, cuando llegó a Santafé la noticia de que una gran ceremonia indígena, supuestamente de carácter religioso, había sido organizada por el cacique del pueblo en presencia de varios caciques y capitanes de la región y de miles de sus súbditos ${ }^{23}$. El incidente propiamente dicho cae por fuera del alcance de este capítulo, pero lo que nos concierne aquí es que fue la Real Audiencia, a través de uno de sus oidores -y no la Iglesia-, la que realizó la investigación del caso y tomó las medidas que consideró necesarias.

Barrios, claro, estaba intentando labrar un lugar para los seculares en el Nuevo Reino frente a la competencia de los regulares por la administración de los sacramentos y la evangelización, y con ellos y las autoridades civiles por el liderazgo de la Iglesia. En agosto de 1560 el rey tuvo que ordenarle que de-

${ }^{22}$ Pacheco (1971) sugiere que se trataba de una cédula del 31 de agosto de 1560 que está recopilada en el cedulario deEncinas (1945, p. 137) y que analiza Sánchez Bella en su estudio de 1991 (p.32).

${ }^{23}$ La documentación de este incidente se encuentra en AGI Justicia 618, 1395r-1438v, y fue editada y publicada por Casilimas (2001) y analizada por Londońo (2001). 
jara de excomulgar gente, pues consideraba que eran causas demasiado livianas y tuvo que reiterar esta orden en 1568 (AGI, SF 234, libro 3, 151v). Estas excomuniones y sanciones eclesiásticas eran todas las herramientas que el obispo tenía a su disposición para afirmar su potestad jurisdiccional, y como es de esperarse las aprovechó.

Sería engañoso representar las relaciones entre Barrios y los regulares como de conflicto constante. La corona aún apoyaba la expansión de la presencia regular en el Nuevo Reino y Barrios la necesitaba. Por ejemplo, en octubre de 1556 la corona le ordenó a la Audiencia que reportara dónde sería útil que se construyeran nuevos conventos, explicando que su construcción sería financiada en partes iguales por la corona, los encomenderos o vecinos españoles del lugar y la población indígena, algo que hubiera contribuido a los propósitos de Barrios de expandir el proyecto evangelizador al igual que a los intereses de los regulares (AGI, SF 533, lib. 2, 7r r) ${ }^{24}$. Pero de la misma manera como surgieron tensiones con los laicos y la Audiencia cuando Barrios intentó afirmar su potestad jurisdiccional, también surgieron problemas con los regulares, incluso cuando lo que Barrios intentaba hacer contaba con el apoyo de la corona o seguía lo prescrito por el Concilio de Trento. Por ejemplo, en julio de 1566 los dominicos de Santafé se quejaron al rey de que sus iglesias estaban siendo vaciadas porque Barrios supuestamente estaba compeliendo a los feligreses españoles a ir a sus parroquias seculares en vez de asistir a las iglesias de los conventos los domingos y días festivos, so pena de excomunión (AGI, SF 188, 590r). Dejando a un lado la cuestión de la veracidad de la supuesta penalidad, que parece excesivamente provocadora, queda claro que Barrios estaba intentando afirmar su poder jurisdiccional sobre la Iglesia y las materias eclesiásticas de su Arquidiócesis y la primacía de los seculares en la vida religiosa de los laicos.

En lo concerniente a la evangelización, es difícil exagerar las limitaciones que tenía el clero secular. Apenas unos meses después de la conclusión del sínodo, en octubre de 1556, el Consejo de Indias le envió a Barrios una petición que había recibido de los habitantes españoles de las ciudades de Tocaima, Pamplona y Vélez, en la cual pedían que se fortaleciera la presencia clerical en sus ciudades, que no alcanzaba a "cumplir con la administración de los sacramentos y con la conversión de los indios". Todo lo que querían era

\footnotetext{
${ }^{24}$ Este sistema de tercios para el financiamiento de las nuevas fundaciones sería el mismo unos años más tarde cuando se sistematizara la construcción de pueblos de indios y la fábrica de iglesias (Romero Sánchez, 2010).
} 
que en vez de tener apenas un sacerdote por ciudad, les asignaran dos (AGI, SF 533, libro 2, 5r). Si la provisión que existía tanto para la población española como la indígena de estos centros importantes era así de escasa (Lee, 1963, p. 14; Mantilla 1994, 87), ¿qué podría esperarse para la población indígena de lugares más apartados de los centros urbanos? Barrios no hizo mucho por mejorar esta difícil situación: cuando murió en 1569, apenas había ordenado a cuatro sacerdotes y el clero secular continuaba concentrándose casi exclusivamente en lo que concernía a la población española (Lee, 1963, p. 30). Pero se avecinaban cambios dramáticos y rápidos.

\section{El CONTROVERSIAL ARZOBISPO LuÍs ZAPATA DE CÁRDENAS}

Hacia el final del episcopado de Barrios y en los años siguientes empezó a cambiar la marea a favor del clero secular de manera decisiva a lo largo de la América española, no solo como resultado de su desarrollo institucional, sino por razones más fundamentales. El Concilio de Trento concluyó en 1563 y el 12 de julio de 1564 Felipe II adoptó sus decretos como leyes del Estado y ordenó su implementación alrededor de sus territorios. El resultado fue dejar a las autoridades civiles y eclesiásticas de América con la tarea común de reformar la Iglesia siguiendo las pautas tridentinas ${ }^{25}$. Esta decisión coincidió y alentó una iniciativa por parte de la corona de desempeñar un papel más activo en el programa evangelizador a través del naciente clero secular, razón por la cual empezó a apoyarlo de manera decisiva. Un paso importante en este proceso fue la introducción de la llamada Cédula magna del patronato de 1574, que fue enviada a todas las diócesis de América y que con base en la serie de privilegios y poderes que había recibido del papado, delineaba la nueva estrategia que tomaría frente al gobierno de la Iglesia y la evangelización. Ahora tendría un papel mucho más importante, especialmente en cuanto a la erección de parroquias y doctrinas y la provisión de clérigos para las mismas (AGI, IG 427, libro 30, 225r-259r).

La modificación representaba una ruptura decisiva con el statu quo, que ya de por sí era tenso y en repetidas ocasiones dio lugar a que surgieran nuevos conflictos y controversias entre las autoridades diocesanas encargadas de

${ }^{25}$ Copias de este decreto circularon de manera amplia y fueron recopiladas y publicadas junto a las constituciones de Trento, por ejemplo en la influyente traducción de López de Ayala (1785, apéndice 8, p. xlix). 
implementar las reformas tridentinas y las órdenes religiosas activas alrededor de América, que ahora se enfrentaban con una amenaza a su independencia, casi sin precedentes ${ }^{26}$. En Santafé, donde la misma llegada del clero secular había causado tensiones, las nuevas reformas tenían el potencial de ser explosivas.

En México, este proceso fue supervisado por el virrey Martín Enríquez y los arzobispos Alonso de Montúfar y Pedro Moya de Contreras; en el Perú, por el influyente virrey Francisco de Toledo y los arzobispos Jerónimo de Loayza y especialmente, Toribio de Mogrovejo. Bajo este último se implementaron reformas sustanciales con el III Concilio Provincial de Lima de 1582-1583 (Estenssoro, 2003, p. 32 y ss., p. 245 y ss.). Aunque el proceso de reforma no fue fácil ni sencillo, en los dos centros del imperio español que lo impulsaron en América contaban con una mano de obra clerical considerable, con el apoyo político de las autoridades civiles, la posibilidad de celebrar concilios provinciales y sínodos diocesanos, así como con los recursos financieros necesarios para establecer seminarios e instituciones educativas y organismos judiciales y disciplinarios adecuados. Incluso podían promulgar legislación sofisticada y publicar textos catequéticos, pues tenían acceso a imprentas, las cuales habían sido introducidas en México por fray Juan de Zumárraga en 1539 y en el Perú en 1581 (Rosenblat, 2002, p. 89; Durston, 2007; Resines, 1992, pp. 236237). Las circunstancias del Nuevo Reino fueron más complicadas.

La persona enviada a Santafé a reemplazar a Barrios y a introducir las reformas fue fray Luís Zapata de Cárdenas (arzobispo 1573-1590). En 1561 había sido nombrado como tercer comisario general de la provincia franciscana del Perú y despachado al Nuevo Mundo con poder sobre todos los franciscanos de América del Sur en un momento en el cual la influencia de la Orden sobre el proyecto evangelizador estaba en su cenit (Garrain, 1990, p. 41). Su tarea había sido supervisar el desarrollo de la Orden y corregir problemas.

Zapata pasó sus años como comisario realizando visitas disciplinarias incluso a los lugares más apartados de las provincias a su cargo. Viajó hasta lugares tan lejanos como Chile y envió representantes suyos a otros lugares, incluido el Nuevo Reino (Garrain, 1990, p. 42). Sus esfuerzos disciplinarios fueron todo un éxito y las autoridades civiles y diocesanas del Perú recomendaron que fuera promovido al episcopado ${ }^{27}$.

${ }^{26}$ Para un bosquejo de este proceso de reconfiguración de la Iglesia, véase Cobo (2012, pp. 60-64).

${ }^{27}$ Véanse por ejemplo la carta del arzobispo Loayza al rey del 2 de agosto de 1564, recopilada por Vargas (1938, p. 85), y del influyente oidor Lope García de Castro del 23 de septiembre de 1565, recopilada por Levillier (1921, pp. 94-110). 


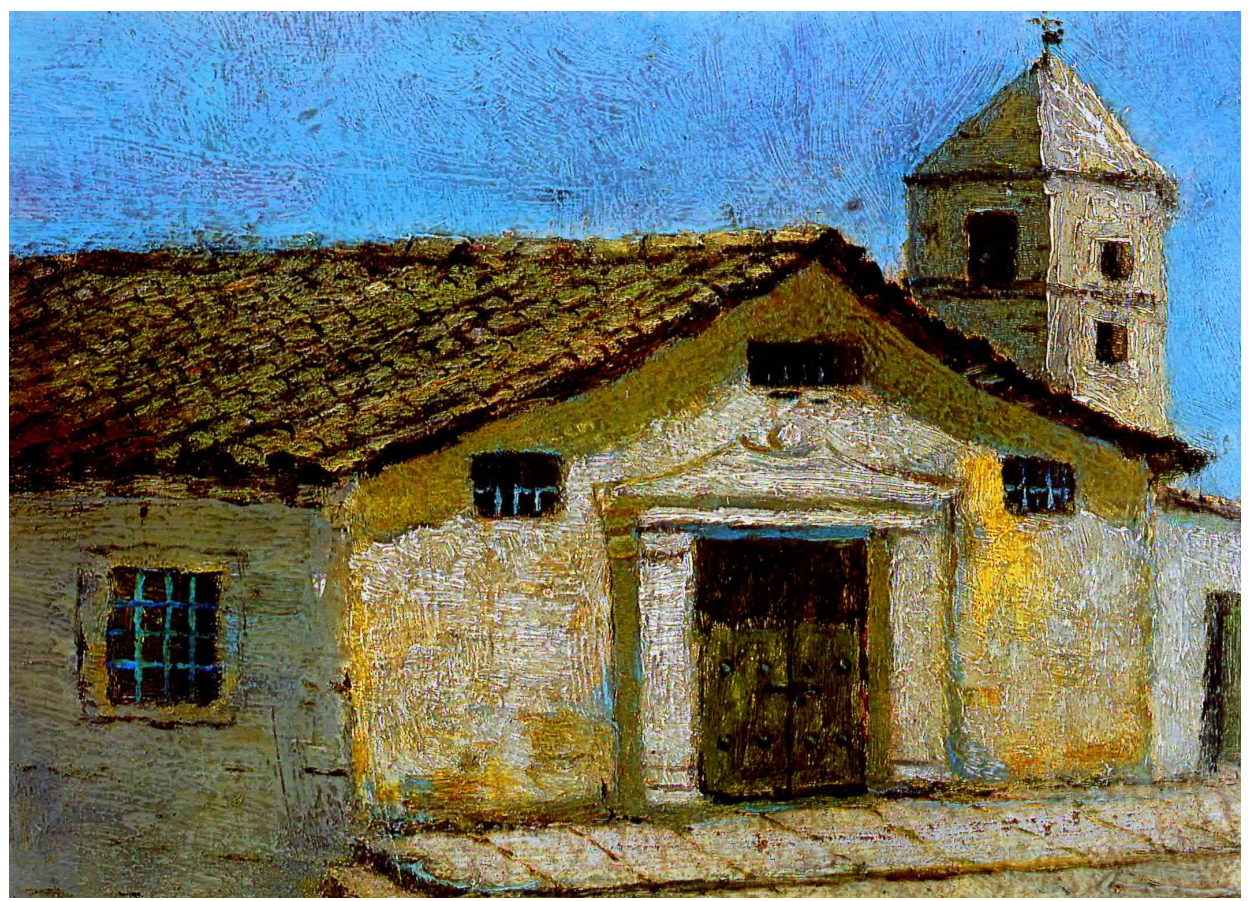

Figura 4. Luis Núnez Borda. (1938). Primera Catedral de Bogotá demolida en el año de 1808. Bogotá: Biblioteca Luis Ángel Arango.

De esta manera, cuando el rey se enteró de la muerte de Juan de Los Barrios escogió a Zapata para reemplazarlo, motivado no solo por los logros en la reforma del esfuerzo evangelizador franciscano y en la estricta aplicación de la disciplina eclesiástica que adornaban su currículo, sino también por haber hecho ambas cosas de manera compatible con la nueva dirección que el rey quería darle al gobierno de la Iglesia en el Nuevo Reino.

La llegada de Zapata trajo una serie de cambios importantes. Su prioridad desde el principio fue quitarle el control del proyecto evangelizador a las órdenes religiosas, despojándolas de las doctrinas que consideraba que no podían administrar adecuadamente y entregándolas al clero secular. También realizó visitas pastorales en varias parroquias y doctrinas de su Arquidiócesis, principalmente con la intención de destruir y decomisar los objetos aparentemente relacionados con la idolatría de la población indígena, aunque también para imponer disciplina a sus sacerdotes. Al ver que se celebraban concilios provinciales en México y Perú, Zapata trató de organizar uno para Santafé, convocado para agosto de 1583 (AGI, SF 226, núm. 44, 5r). También inten- 
tó producir un corpus catequético para el uso de sus sacerdotes, tal como lo habían hecho sus homólogos en otros lugares de América. Incluso fundó un seminario diocesano en 1581, siguiendo lo dictado por el Concilio de Trento (AGI, SF 226, núm. 40).

Sin embargo, Zapata se estaba enfrentando a una lucha cuesta arriba. Esto era en parte el resultado de las circunstancias del Nuevo Reino durante su episcopado. Había poco dinero, escasa mano de obra clerical y las órdenes religiosas tenían aliados poderosos en el gobierno civil. Su intento de convocar un concilio provincial fracasó, víctima de un conflicto jurisdiccional con la arquidiócesis de Lima, pues el obispo de Popayán -que se encontraba exiliado en Quito debido a una disputa con las autoridades civiles de su diócesis- se reusó a reconocer a Zapata como su metropolitano y a participar en el concilio, por lo que este finalmente tuvo que ser cancelado en marzo de 1584 (AGI, SF 226, núm. 49).

En vez de un corpus de material catequético impreso, traducido a lenguas indígenas y de legislación sofisticada para reformar la evangelización, Zapata se tuvo que conformar con lo que podía producir él mismo: su Catecismo e instrucciones de 1576 (2008). Incluso su intento de establecer un seminario diocesano como mandaban las constituciones tridentinas falló, puesto que el seminario tuvo que cerrar en 1586 debido a la falta de dinero para sostenerlo (AGI, SF 226, núm. 57). Sus relaciones con las autoridades civiles fueron conflictivas y la Audiencia le quitó a la fuerza el control de una campaña que organizó a finales de la década de 1570 para investigar la supuesta idolatría de la población indígena alrededor de la Arquidiócesis (Rojas, 1965, p. 347 y ss.).

Una reforma importante que se introdujo durante el episcopado de Zapata fue una nueva política lingüística que buscaba incorporar el uso de las lenguas indígenas en la evangelización (Cobo, 2014; Lee, 1964). Los misioneros españoles que se enfrentaban al problema que suponía superar las barreras lingüísticas para poder llevar a cabo su misión entre la población indígena del Nuevo Mundo habían adoptado, desde el principio, una política doble: por un lado enseñar español a la población indígena y fomentar su adopción y al mismo tiempo, aprender y luego utilizar las lenguas indígenas para alcanzar sus propósitos. Después de un primer intento fallido por parte de la corona en la década de 1550 que buscaba favorecer la enseñanza y el uso del español y prohibir la evangelización en lenguas indígenas, la corona cambió de parecer y apoyó su uso.

La nueva Resolución Real empezó en 1574 con la Cédula magna cuyo artículo 19 ordenaba a las autoridades de cada región que cuando nombraran doctrineros prefirieran candidatos "que supieran la lengua de los indios que 
han de doctrinar" (AGI, IG 427, libro 30, 258r). Se promulgaron documentos legislativos adicionales sobre el tema en los ańos siguientes: en 1578 por ejemplo, el Rey le ordenó al Arzobispo que no nombrara candidatos ignorantes de las lenguas indígenas a doctrinas (Lee, 1964, p. 186). Luego otras cédulas incrementaron los requisitos lingüísticos, primero para frailes que quisieran viajar a América como misioneros, candidatos que quisieran ser ordenados sacerdotes en el Nuevo Mundo y finalmente, frailes y sacerdotes seculares ya instalados en doctrinas. Por último, en 1580 se promulgó legislación que requería a las autoridades de cada región establecer un marco práctico para la enseñanza de lenguas indígenas para entrenar misioneros y examinarlos (Cobo, 2012, pp. 62-63).

A raíz de la nueva política, los concilios provinciales de México y Lima de la década de 1580 produjeron sendos cuerpos de material catequético estandarizado para ser utilizado en las doctrinas, material que se debía publicar en las "lenguas generales" de cada lugar. Zapata había apoyado la idea de utilizar lenguas indígenas en la catequización y predicación incluso antes de que se expidiera la mayor parte de esta legislación (véase por ejemplo AGI, SF 226, núm. 12). Pero la nueva política fue polémica entre los regulares, muchos de los cuales habían sido responsables por la estrategia anterior de predicar y catequizar exclusivamente en español. El resultado fue una controversia amarga sobre la nueva política lingüística que se inflamó más cuando Zapata aprovechó los requisitos de la legislación para despojar a los regulares de más doctrinas, bajo el pretexto de que sus doctrineros eran ignorantes de las lenguas indígenas (Cobo, 2014).

De una manera similar, varios de los problemas a los que se enfrentó el arzobispo Zapata fueron de su propia creación. Desde su perspectiva, las circunstancias difíciles requerían soluciones audaces y aquellas que el Arzobispo escogió fueron realmente drásticas. Para resolver los problemas de la Iglesia del Nuevo Reino, Zapata decidió ordenar por lo menos 124 hombres al sacerdocio entre su llegada a Santafé en 1573 y su muerte en 1590 e instalarlos en doctrinas, con frecuencia doctrinas que estaban en manos del clero regular. De manera controversial, 22 de los hombres que ordenó eran mestizos y 39 eran criollos (Lee, 1963, pp. 32-55). La justificación del Arzobispo siempre fue su dominio de las lenguas indígenas, algo que reiteraría en repetidas ocasiones, especialmente a medida que sus ordenaciones de mestizos se convirtieron en el punto focal del antagonismo de las órdenes religiosas y las autoridades civiles y una disputa inmensa que llegó a involucrar hasta al Rey y al Papa (Cobo, 2012). Las órdenes religiosas, claro, reaccionaron violentamente a estas afrentas. 
De esta forma, sí hubo algunos cambios importantes para la Iglesia y la evangelización durante los 17 años del episcopado de Zapata en Santafé. Algunas de sus reformas tuvieron efectos perdurables, como el nuevo énfasis en el valor de las lenguas indígenas que seguiría cobrando importancia en las décadas siguientes. Otros esfuerzos fueron menos exitosos, en parte porque con sus métodos, Zapata alienó a muchos miembros de las órdenes religiosas y de las autoridades civiles.

Un largo periodo de sede vacante siguió a la muerte de Zapata en 1590, durante el cual el clero secular careció de liderazgo. Varios de los miembros del capítulo de la catedral que gobernó la Arquidiócesis en este periodo intentaron continuar algunas de las políticas de Zapata. Por ejemplo, desde 1591 el maestrescuela Francisco de Porras Mejía empezó a pedirle ayuda a la corona para restablecer el seminario diocesano que había tenido que cerrar, incluso llegando a proponer que lo administrara la Compañía de Jesús, prefigurando lo que de hecho ocurriría a principios del siglo XVII (AGI, SF 231, núm. 27).

Como era de esperarse, también empezaron a llegar quejas a la península por parte de las órdenes religiosas que aún buscaban resistirse a las reformas y a la autoridad secular que Zapata había intentado imponer, e incluso "de nuevo arraigarse en los pueblos de los indios" -como se quejó el capítulo catedralicio en 1598 - despolvando privilegios concedidos en la década de 1560 para justificar legalmente sus acciones (AGI, SF 231, núm. 37, 1r). Con estrategias como estas, lograron recuperar muchas de las doctrinas que Zapata les había quitado. Más aún, una vez más las órdenes religiosas se estaban rehusando reconocer la jurisdicción de las autoridades diocesanas, ignorando sus cortes y mecanismos disciplinarios a favor de los propios. Y para rematar, las autoridades civiles, ahora encabezadas por el nuevo presidente de la Audiencia, Francisco de Sande, las estaban apoyando (AGI, SF 231, núm. 37, 1r-1v). Zapata, en su afán por implementar reformas ambiciosas con métodos poco convencionales, no había logrado establecer un marco institucional perdurable para su reforma de la Iglesia y de su programa evangelizador.

De todas formas, a pesar de estos problemas y reveses, es indudable que el clero secular del Nuevo Reino al final del siglo XVI era más fuerte y contaba con un marco institucional más firme que nunca. Cuando el siguiente arzobispo de Santafé se quejaba en los últimos años del siglo de muchos de los mismos problemas que Zapata encontró en 1573, su situación y los recursos y herramientas a su disposición para resolverlos eran muy distintos.

Gran parte del desarrollo institucional de la Iglesia bajo el arzobispo Zapata fue guiado y facilitado por el movimiento de reforma y renovación religiosa 
liderado por el Concilio de Trento y la manera en que este fue adoptado y aprovechado por la corona espańola para promover sus intereses. Sin embargo, dicha influencia aún no se hacía sentir en lo que concierne a la ideología y las preocupaciones de la evangelización, en lo que había presentado cambios drásticos desde el episcopado de Juan de Los Barrios.

La principal declaración doctrinal de Zapata fue su Catecismo e instrucciones de 1576 que reflejaba las mismas preocupaciones que subyacen a las constituciones del sínodo de 1556. Zapata lo compuso "para la edificación, conversión y conservación de los naturales que en él habitan” y también partía de la idea de que la población indígena era susceptible a caer en "todo género de pecados, ritos y ceremonias gentílicas, sacrificios y malas costumbres tocantes al culto del demonio" (Zapata, 2008, pp. 271-273). Para contrarrestar esta tendencia, Zapata propuso una serie de directivas que buscaban inculcar policía junto a la doctrina cristiana, empezando con cuestiones prácticas relativas por ejemplo, a la manera en la que la población indígena debía vestir y cómo se debían organizar sus pueblos, antes de discutir exactamente qué se debía incluir en la catequesis, qué sacramentos se debían administrar y sobre qué temas se les debía predicar. La lógica aquí una vez más, era que el desarrollo político y el desarrollo espiritual de la población indígena debían complementarse el uno al otro y que existían obstáculos los cuales podían socavar a ambos. Por este motivo, se debía eliminar aquello que Zapata concebía como influencias malignas, entre ellos varios aspectos de la vida indígena que el Arzobispo consideraba incompatibles con la nueva religión (Marín, 2008). Nada de esto, claro, era nuevo. De hecho, muestra ser igual a la lógica de la legislación de 1556, aunque las instrucciones de Zapata cubrían una gama más amplia de materias relativas a la vida cotidiana de la población indígena.

Asimismo, seguía en pie la reticencia a admitir a la población indígena en otros aspectos de la vida religiosa cotidiana. Si bien es cierto que se podían percibir algunos cambios -como la exhortación del Arzobispo a sus sacerdotes para que enseńaran a sus catecúmenos a adorar el Santísimo Sacramento con algunas oraciones apropiadas (Zapata, 2008, p. 302)- ninguno de ellos era de carácter radical. La prohibición de admitir a la población indígena a la Eucaristía había sido modificada, pero no para hacerla menos tajante: "porque estos indios son imperfectísimos en conocer y estimar el bien que en este santísimo sacramento hay"; no se les debía dar la Eucaristía excepto cuando la persona en cuestión hubiera sido examinada y aprobada por su doctrinero y además, dada licencia expresa para comulgar por parte del arzobispo, "y no de otra manera alguna" (p. 302). Esto solo empezaría a cambiar a partir del comienzo del siglo XVII. 


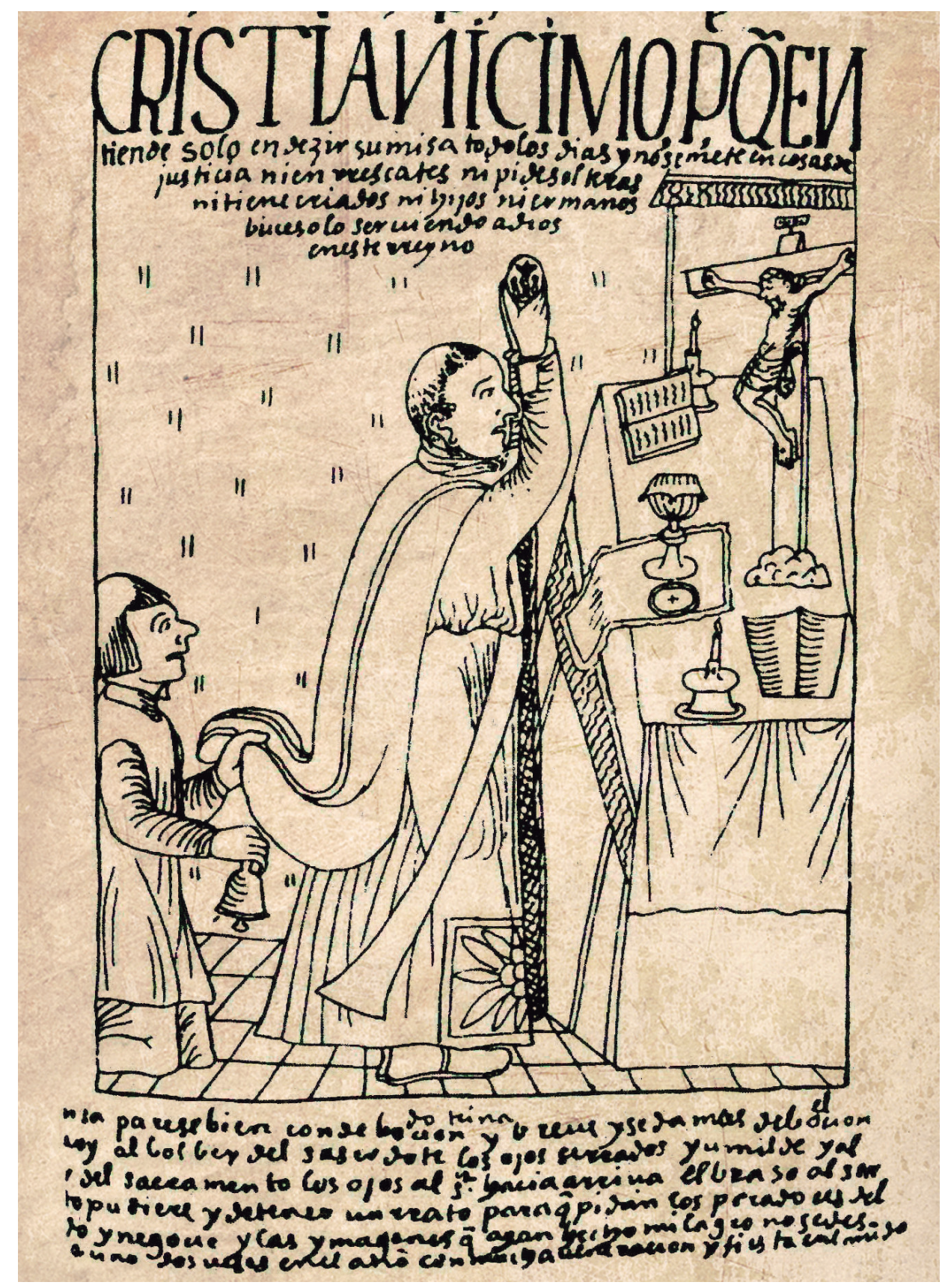

Figura 5. Felipe Guamán Poma de Ayala. (1614) Nueva Crónica y Buen Gobierno: Cristianísimo padre que entiende sólo decir misa todo el día. En: Marta Herrera Ángel, 2003, "Muiscas y cristianos del biohote a la misa y el tránsito hacia una sociedad individualista". Boletín de Historia y Antigüedades, 90 (822), p. 513. 


\section{CONCLUSIÓN}

El clero secular del Nuevo Reino de Granada, que solo había nacido a mediados del siglo XVI, se fortaleció y desarrolló institucionalmente de manera apreciable hacia el final del siglo. Juan de Los Barrios y Luis Zapata de Cárdenas lo dotaron, primero de un marco legislativo y luego de personal adecuado, en su intento por afirmar el liderazgo de la autoridad episcopal sobre el proyecto evangelizador y la vida religiosa de la región. Ambos arzobispos se esforzaron también por hacer valer su potestad jurisdiccional frente a la competencia de las órdenes regulares y de las autoridades civiles, en especial después de que la corona espańola decidiera apoyar al clero secular para desempeńar un papel más activo en el gobierno eclesiástico y en el proceso de evangelización luego del Concilio de Trento.

No todas las políticas de los dos arzobispos fueron exitosas, en gran parte debido a las difíciles circunstancias del Nuevo Reino, no obstante sentaron las bases para que sus sucesores continuaran fomentando el desarrollo del clero secular. Sin embargo, incluso a finales del siglo, la evangelización de los indios seguía fuertemente influenciada por una serie de prioridades y preocupaciones, así como por algunas suposiciones acerca de la población indígena y su vida religiosa que ya empezaban a parecer anticuadas y anacrónicas para algunos observadores, entre ellos Bartolomé Lobo Guerrero, el tercer arzobispo de Santafé (arzobispo 15961607), quien llegó a la ciudad en los últimos meses del siglo. El predominio del clero secular representó una ruptura con el statu quo en términos institucionales, pero en lo ideológico los cambios radicales aún estaban por empezar.

\section{REFERENCIAS}

Archivo General de Indias, Sevilla (AGI): Indiferente General (IG) 419, 427; Justicia 618; Santafé (SF) 188, 226, 231, 234, 533, 552; Patronato 197.

Bataillon, M. (1966). Erasmo y España: Estudios sobre la historia espiritual de siglo XVI. México: Fondo de Cultura Económica.

Borges, P. (1977). El envio de misioneros a América durante la época española. Salamanca: Universidad Pontificia.

Brading, D. (1991). The first America: the Spanish monarchy, creole patriots and the liberalstate, 1492-1866. Cambridge, Reino Unido: Cambridge University Press.

Cañeque, A. (2004). The king's living image: the culture and politics of viceregal power in colonial Mexico. Londres: Routledge. 
Casilimas, C. I. (2001). Juntas, borracheras y obsequias en el cercado de Ubaque. Boletín del Museo del Oro (49), 13-48.

Castañeda, P. (1971). La condición miserable del indio y sus privilegios. Anuario de Estudios Americanos, 28, 245-335.

Charles, J. (2010). Allies at odds: the Andean church and its indigenous agents, 1583-1671. Albuquerque: University of New Mexico Press.

Christian, W. A. (1981). Local religion in sixteenth-century Spain. Princeton: Princeton University Press.

Cobo, J. F. (2012). Mestizos heraldos de Dios: la ordenación de sacerdotes descendientes de españoles e indígenas en el Nuevo Reino de Granada y la racialización de la diferencia, 1573-1590. Bogotá: Instituto Colombiano de Antropología e Historia, ICANH.

Cobo, J. F. (2014). Colonialism in the periphery: Spanish linguistic policy in New Granada, c. 1574-1625. Colonial Latin American Review (en imprenta).

Constituciones sinodales fechas en esta ciudad de Santafé, por el señor don Fray Juan de Los Barrios [...] a 3 de junio de 1556. (1556). En M. G. Romero. Fray Juan de Los Barrios y la evangelización del Nuevo Reino de Granada (pp. 459-562). Bogotá: Academia Colombiana de Historia.

Davenport, F. G., y Paullin, C. O., (Eds.) (1917). European treaties bearing on the history of the United States and its dependencies to 1648. Washington, D.C: Carnegie Institution of Washington.

Durston, A. (2007). Pastoral Quechua: the history of Christian translation in colonial Peru, 1550-1650. Notre Dame: University of Notre Dame Press.

Elliott, J. H. (1963). Imperial Spain, 1469-1716. Londres: Edward Arnold. Encinas, D. (1945). Cedulario indiano. Madrid:Ediciones Cultura Hispánica.

Erasmo, D. (1988/1503). The handbook of the Christian Soldier: Enchiridion militis christiani. En J. O'Malley (Ed.), Spiritualia: Collected works of Erasmus (pp. 1-127). Toronto: University of Toronto Press.

Estenssoro, J. C. (2001). El simio de Dios: los indígenas y la Iglesia frente a la evangelización del Peru, siglos XVI-XVII. Bulletin de l'Institut Francais d'Etudes Andines, 30 (3), 455-474.

Estenssoro, J. C. (2003). Del paganismo a la santidad: la incorporación de los indios del Perú al catolicismo, 1532-1750. Lima: Instituto Francés de Estudios Andinos, Pontificia Universidad Católica del Perú, Instituto Riva-Agüero.

Figuera, G. (1965). La formación del clero indígena en la historia eclesiástica de América, 1500-1810. Caracas: Archivo General de la Nación.

García, A. (1988). Los privilegios de los franciscanos en América. Archivo Ibero-Americano, 48 (48), 369-390.

García, J. (1892). Códice Mendieta: documentos franciscanos, siglos XVI y 
XVII. México: Imprenta de Francisco Díaz de León.

Garrain, L. J. (1990). Documentos sobre Fray Luís Zapata de Cárdenas y otros evangelizadores llerenses en los archivos de Llerena. En Extremadura en la evangelización del nuevo mundo: Actas y estudios. Congreso celebrado en Guadalupe durante los días 24 al 29 de octubre de 1988 (pp. 379-400). Madrid: Turner, Junta de Extremadura.

Hanke, L. (1974). All mankind is one; a study of the disputation between Bartolomé de las Casas and Juan Ginés de Sepúlveda in 1550 on the intellectual and religious capacity of the American indians. DeKalb: Northern Illinois University Press.

Kamen, H. (1993). The phoenix and the flame: Catalonia and the Counter Reformation. New Haven: Yale University Press.

Lee, A. (1963). Clero indígena en el Arzobispado de Santafé en el Siglo XVI. Boletin de Historia y Antigüedades, 50 (579-581), 3-86.

Lee, A. (1964). Gonzalo Bermúdez, primer catedrático de la lengua general de los Chibchas. Boletin de Historia y Antigüedades, 51 (594-597), 183-217.

Levillier, R. (1921). Gobernantes del Perú, cartas y papeles, siglo XVI: documentos del Archivo de Indias. Madrid: Sucesores de Rivadeneyra.

Londońo, E. (2001). El proceso de Ubaque de 1563: la última ceremonia religiosa pública de los muiscas. Boletín del Museo del Oro, (49), 1-12.

López de Ayala, I. (Ed.) (1785). El sacrosanto y ecuménico Concilio de Trento. Madrid: La Imprenta Real.

MacCormack, S. (1991). Religion in the Andes: vision and imagination in early colonial Peru. Princeton: Princeton University Press.

Mantilla, L. C. (1994). Historia de la Arquidiócesis de Bogotá: su itinerario evangelizador, 1564-1993. Bogotá: Arquidiócesis de Bogotá.

Marín, J. J. (2008). La construcción de una nueva identidad en los indigenas del Nuevo Reino de Granada: la producción del catecismo de fray Luis Zapata de Cárdenas (1576). Bogotá: Instituto Colombiano de Antropología e Historia, ICANH.

Mayorga, F. (2013/1991). La Audiencia de Santafé en los siglos XVI y XVII, Bogotá: Imprenta Distrital, Secretaría General de la Alcaldía Mayor de Bogotá.

Metzler, J. y Roselli, G. (1991). America Pontificia. Ciudad del Vaticano: Libreria Editrice Vaticana.

Muldoon, J. (1979). Popes, lawyers and infidels: the Church and the non-Christian world, 1250-1550. Philadelphia: University of Pennsylvania Press.

Nalle, S. T. (1992). God in La Mancha: religious reform and the people of Cuenca, 1500-1650. Baltimore: Johns Hopkins University Press.

Pacheco, J. (1971). Historia Extensa de Colombia (vol. XIII).i: La evangelización del Nuevo Reino, siglo XVI. Bogotá: Academia Colombiana de Historia. 
Pagden, A. (1982). The fall of natural man: the American indian and the origins of comparative ethnology. Cambridge: Cambridge University Press.

Pardo, O. F. (2004). The origins of Mexican Catholicism: Nahua rituals and Christian sacraments in sixteenth-century Mexico. Ann Arbor: University of Michigan Press.

Phelan, J. L. (1970). The millennial kingdom of the Franciscans in the New World. Berkeley: University of California Press.

Resines, L. (1992). Catecismos americanos del siglo XVI. Salamanca: Junta de Castilla y León, Consejería de Cultura y Turismo.

Rojas, U. (1965). El Cacique de Turmequé y su época. Tunja: Departamento de Extensión Cultural de Boyacá.

Romero, M. G. (1960). Fray Juan de Los Barrios y la evangelización del Nuevo Reino de Granada. Bogotá: Academia Colombiana de Historia.

Romero, G. (2010). Los pueblos de indios en Nueva Granada. Granada: Editorial Atrio.

Rosenblat. (2002). La hispanización de América: el español y las lenguas indígenas desde 1492. En M. J. Tejera (Ed.), El español de América (pp. 78116). Caracas, Venezuela: Biblioteca Ayacucho.

Sá, I. (2007). Ecclesiastical structures and religious action. En F. Bethencourt y D. R. Curto (Eds.), Portuguese oceanic expansion, 1400-1800 (pp. 255-282). Cambridge, Reino Unido: Cambridge University Press.

Sánchez, I. (1991). Iglesia y Estado en la América española. Pamplona: Ediciones Universidad de Navarra.

Traslosheros, J. E. (2004). Iglesia, justicia y sociedad en la Nueva España: la audiencia del arzobispado de México, 1528-1668. México D.F.: Editorial Porrúa; Universidad Iberoamericana.

Van Oss, A. C. (1986). Catholic colonialism: a parish history of Guatemala, 1524-1821. Cambridge, Reino Unido: Cambridge University Press.

Vargas, R. (1938). Biblioteca peruana: manuscritos peruanos del Archivo de Indias. Lima: Empresa Periodística La Prensa.

Vargas, R. (1951). Concilios limenses (1551-1772). Lima:Tipografía Peruana.

Zamora, A. (1945). Historia de la Provincia de San Antonino del Nuevo Reino de Granada. Bogotá: Editorial ABC.

Zapata, L. (2008/1576). Catecismo e instrucciones. En J. J. Marín Tamayo. La construcción de una nueva identidad en los indígenas del Nuevo Reino de Granada: la producción del catecismo de fray Luis Zapata de Cárdenas (1576) (pp. 271-344). Bogotá: Instituto Colombiano de Antropología e Historia, ICANH. 